Letters to the Editor

\title{
Putting things in perspective
}

\section{AUTHOR \\ Philippe C. \\ Baveye $^{\varrho, 1}$ \\ philippe.baveye@ \\ agroparistech.fr}

@ Corresponding Author

${ }^{1}$ Unité ECOSYS,

AgroParisTech, Université

Paris-Saclay, Avenue

Lucien Brétignières.

Thiverval-Grignon 78850,

France.

\section{Received: 17.03.2017 | Revised:24.05.2017 | Accepted:24.05.2017}

Since mid-February 2017 , the soil science community has been shaken by an unprecedented crisis, spurred by anonymous and for the most part unfounded allegations of dishonest behavior levied against a number of editors of soil science journals. Several of these individuals being Spanish, this crisis has particular significance in Spain, where regrettably it appears to have already caused damage, not only to the reputation of individual researchers who did nothing wrong, but also to the image of our discipline, because of the unprofessional way the problem was handled from the start.

The flurry of e-mails that have been written on this crisis have tended to focus so far on the failure of some individuals to "abide by the rules", be it the editors accused of wrongdoing, or the anonymous accuser for tarnishing our discipline. That is one way to look at this whole affair. There is however another, less myopic, perspective, which I would suggest would be much more beneficial to soil science in the long run.

The focus should be, I believe, on what at least some people consider as the norm in scholarly publishing. In scientific research in general, the unwritten rule at the moment seems to be that the only articles worth paying attention to are those written in proper English, published in journals with a high Impact Factor (IF), by authors with a very high $h$-index (i.e., whose articles are abundantly cited). If we look at it a bit closer, no part of this unwritten rule makes any sense. Even the first part is questionable, in this day and age. Unlike 10 or 20 years ago, when the use of English was unavoidable to communicate effectively, it is now relatively easy, with one of many translation tools available freely on the web and getting steadily better every day, to understand any article, regardless of the language (including Catalan and Galician) in which it has been written. It is also well known that the IF factor of a journal, while it may be useful to its publisher to sell it, bears no relation whatsoever to the quality of individual articles published in it. Indeed, a significant percentage of articles in the "top" journals never get cited, even by their own authors! And, clearly, if too much attention is paid to the highly artificial h-index, the only ones who will have a say in science are the mass producers of junk science, or heads of institutes and managers of large research programs, who may not have done any research themselves in decades and may be completely disconnected from it, yet get their name added automatically to the list of authors of a multitude of publications. 
Silly rules invite silly responses. In a country where a decree would give the right to vote only to people who are taller than $1.9 \mathrm{~m}$, one should not be surprised to see more and more men and women wearing high-heel shoes, however impractical that might be! Predictably enough, in science, the unwritten rule has prompted scientists to come up with silly ways to rig the system, from "citation stacking" by editors to increase the IF of their journal, to the creation of "citation clubs" by groups of researchers to mutually increase their h-indexes, to "salami-slicing" of research results down to the "least publishable unit" in order to artificially increase the number of publications, and therefore of possible citations. Some researchers routinely hype up their results beyond reason in order to get articles published in journals, like Science or Nature, with extremely high IF. And, presumably to ease the peer-review process and publish ever faster, even though nobody seems to have much time to read any more (Baveye 2014), some editors do not hesitate to publish large numbers of non-editorial articles in their own journals.

These are all aberrations. In several disciplines, researchers have decided, more or less consciously, to avoid falling into the multiple traps they represent. Mathematicians and anthropologists, for example, appear to pay little or no attention to either IF or $h$-indexes, which in these fields are largely meaningless. As the recent article by Charlet et al. (2016) illustrates, some giants in our discipline or in related fields have shown us by their own examples how it is possible to have highly successful careers without succumbing to the evils of the time. Unfortunately, other soil scientists, for motives that beside being selfserving are not entirely clear, have encouraged us in recent years through a steady stream of publications and widely-circulated pamphlets, to pay significant attention to metrics like the h-index or to the ranking of journals according to their $I F$, and to get outraged by the sudden, supposedly unwarranted rise of some journals (like the Journal of Soils and Sediments a few years back, or more recently of Land Degradation and Development) in this ranking.

We should resist following this latter path. Instead of spending much time worrying about the ranking of journals and of what some people may or may not have done to influence it (incited, I suspect, by IF-obsessed publishers, who did nothing to stop the practice), we should take advantage of the present crisis to shift the focus in our discipline on what really matters. Humanity is faced with very significant environmental and food security problems, and we, soil scientists, have a huge amount of work ahead of us to help resolve these problems, in a very short period of time (e.g., Baveye 2015). We need very solid research and we have to urgently attract to our discipline young researchers who are both well trained and highly creative. Last but not least, we have to convince the powers-that-be to start funding the research in soil science at a level that is adequate to address and solve the crucial societal issues with which we are confronted. This has not been the case in decades.

Given this bigger picture, it should be absolutely immaterial if the results of our work are published in journals with an insanely high IF, or in ones like the Spanish Journal of Soil Science, which currently has no IF. We might find inspiration in that respect from Werner Stumm, a 20th-century giant of aquatic chemistry, who had no qualms publishing a number of landmark articles in Croatica Chemica Acta - a journal ranked fourth-tier by the Web of Knowledge -, apparently without ever worrying about the impact or reputation of the journal (Charlet et al. 2016).

What matters infinitely more than the IF of journals is that each and every one of our articles (hopefully in smaller numbers than now!) be solid contributions to science and 
accessible easily (and for free) by the largest number of people who need the information. To insure quality, we need to be willing to spend time reviewing manuscripts, and to do so in a constructive, helpful manner. The urgency of the situation relative to soils worldwide makes it absolutely irresponsible for us to continue sizing our "competitors" up by their number of papers or $h$-index like kindergarten boys comparing the size of their biceps, and shooting them down under the cover of anonymity when given the opportunity. Whenever we review manuscripts for journals, proposals for funding agencies, or hiring/promotion packages for research institutions, we should not pay any attention to the h-index or number of publications of their authors, but should focus strictly only on the ideas that are presented. As long as these ideas have merit (this, of course, is essential), we should suggest ways to improve them as constructively as possible, or find ways eventually to propose our assistance to make the research progress faster. Rather than constant and childish competition, unavoidably inviting cheating as Schurr and Ritov's (2016) recent observations suggest, what is needed is to foster a true spirit of collaboration across our discipline. In that respect, it is my experience on various proposal review panels that disciplines, like oceanography or meteorology, where a much stronger "esprit de corps" prevails over big egos, fare better in terms of funding than soil scientists, who tend to bicker endlessly about each other's work.

In that context, the real crisis in soil science, as I see it, is related to the fact that we tend to loose track of the bigger picture, and pay undue attention to unimportant details and individual promotion. We should instead be constantly asking ourselves, collectively, whether the research we do is going in the right direction, and whether, as a community, we are combining forces in the best possible way to achieve results and appeal to great minds. Our discipline has spent so much time over the years on issues like the spatial variability of soils, the use of biochar (presented as a cure to almost everything), the application of molecular biology recipes to soils, or the digital mapping of soil properties, and some individuals have gotten hugely inflated $\mathrm{h}$-indexes as a result. But we have spent virtually no time at all reflecting on whether the work we do in these areas is even remotely meaningful and on the right track to answering some of the broader, crucial questions society needs us to resolve. Nor have we spent any time coordinating our work, so that we are all contributing to progress, and the young generations get a chance to contribute from the onset of their careers to the overall effort. That is what we ought to be doing, instead of worrying about IF, $h$-indexes, and other Quixotic windmills.

\section{REFERENCES}

- Baveye PC. 2014. Learned publishing: Who still has time to read? Learned Publishing 27(1):48-51.

- Baveye PC. 2015. Grand challenges in the research on soil processes. Frontiers in Environmental Science 3:10.

- Charlet L, Baham J, Giraldez JV, Lo W-C, Aristilde L, Baveye PC. 2016. Éloge de la méthode: A tribute to Garrison Sposito on the occasion of his retirement. Frontiers in Environmental Science 4:73.

- Schurr A, Ritov I. 2016. Winning a competition predicts dishonest behavior. Proceedings of the National Academy of Sciences 113(7):1754-1759. 